\title{
Teaching undergraduates child health: what, how, where, and when?
}

\author{
Hugh Davies
}

It is during undergraduate days that the enthusiasm develops which takes students on to look at paediatrics as a career option. Fostering this and promoting critical analysis of child health is the challenge of undergraduate education. The defects in medical education have been outlined $^{1-3}$ and the General Medical Council (GMC) have recently issued directives to address these criticisms. ${ }^{4}$ These offer paediatricians an opportunity to improve the teaching of child health. This chance should not be allowed to slip through our fingers.

The three underlying principles of the GMC directives are: (a) reduction of didactic teaching and adoption of problem orientated approaches; (b) introduction of a core curriculum supplemented by special study modules; and (c) promotion of vertical and horizontal integration.

\section{What should we teach?}

\section{(1) A WAY OF THINKING}

The GMC wishes to promote the development of the student's critical facilities, ${ }^{5}$ skills in research, problem solving techniques, ${ }^{6}$ and the ability to learn independently. ${ }^{7}$ These are approaches common to all specialties and would suggest paediatric teachers will need to instruct students in analysing clinical problems and to encourage the study of logic and reasoning. There is probably no better model than Conan Doyle's Sherlock Holmes! The directives place emphasis on problem based learning to achieve this; these techniques are unpopular with examination focused students and teachers will need to be conversant with them if they are to win students over.

There is also a need to help students empathise with children and their families, deal sympathetically with their problems, and clearly explain plans of management. These goals are central to the new curriculum. Funds have been provided and paediatricians could make use of the resources being developed to teach communication skills. ${ }^{8-10}$

\section{(2) THE PAEDIATRIC CORE CURRICULUM}

The value and limitations of educational objectives when drawing up a curriculum have been discussed by Foulds, concluding 'objectives should be considered a useful tool for curriculum development ... not an academic straitjacket'. ${ }^{11}$ Like clinical guidelines, objectives handed down from 'the centre' are unlikely to gain acceptance and would certainly not be taught with any enthusiasm. They should therefore be drawn up locally by as many staff members as possible. The GMC directives provide an opportune stimulus to start the process. As an example St Mary's and Central Middlesex Hospital paediatric units have drawn up the following four broad aims and objectives:

(i) To provide an introduction to families, how family members interact and cope with acute and chronic illness

Students should be able to describe differing family structures with their strengths and weaknesses. They should have an understanding of the stresses and anxieties of child rearing and the changes that occur in families with children.

(ii) To teach the structure of child health services in the UK

Students should be able to describe the role of the general practitioner and hospital paediatrician in caring for sick children, they should be able to describe the community paediatrician's role and how children are referred to each. They should be able to describe the responsibilities of the health, education, and social service departments and how they work together.

\section{(iii) To teach the skills of history taking,} examination, and management

Students should have the intellectual and practical skills that will allow delineation of a child's problem, list possible causes, provide a management plan, and explain it to the family.

\section{(iv) To provide educational objectives for} students to direct their learning in growth, development, and each organ system

In the respiratory system, for example, students should be able to explain the physiological differences between the respiratory system of children and adults and describe the immunological development of the infant and child and how and why this impinges on respiratory illness. They show also know in outline the pathophysiology, epidemiology, presentation, and treatment of the common acute respiratory infections along with possible preventive measures.

In asthma students should know and justify a definition of asthma and be aware of the common pattern of presentation of asthma and explain possible treatments. They should also 
be able to assess and start management of an acute asthmatic.

In cystic fibrosis students should know the pathophysiology and the underlying molecular mechanisms of cystic fibrosis and the common presentations of this condition.

They should also be able to take the common respiratory signs or symptoms, further elucidate them, establish possible causes and construct management and treatment plans.

\section{How should students be taught?}

What methods are available, what evidence is there that one method is any better than an other, and what are the most appropriate techniques to teach knowledge, skills, and attitudes?

\section{KNOWLEDGE}

Lectures are perceived to be the most efficient means of information transfer, although their classical structure needs radical revision. ${ }^{12} 13$ Individual tuition is impossible, the lecturer must aim at 'the average student', and development of critical thought is limited: 'lectures are a means of getting information from the lecturer's notes into those of the student without passing through the brains of either'.

There is now pressure to move toward more problem orientated small group teaching but it is unrealistic to imagine lectures will be completely replaced; students are comfortable with them and from the department's point of view they are easy to arrange. Small group work involves more staff and greater expense. Lectures will need to be made more problem orientated and developed to promote self directed learning. This requires teaching the teacher; it will no longer be possible to claim that 'anyone can teach'. Modern technology could allow the lecturer to prepare a summary structure of the lecture with problems for students to work up beforehand and then present during the lecture. Attending students could add detail to the summary during the lecture and later edit their notes on a computer to create their own 'textbook'.

\section{SKILLS AND ATTITUDES}

The classical clinical skills of diagnosis, examination, and management will continue to be best taught 'at the bedside' but more effort will be needed to promote self directed learning. Petersen and Howard provide an example of this in physiology that could be adapted to clinical teaching. ${ }^{14} \mathrm{We}$ should also make use of the clinical skills laboratories now established. Poster presentation is a valuable educational method to teach critical analysis, presentation skills, and time management. ${ }^{15}$ It is not labour intensive and given free reign to decide their own projects we have found the students produce original work enthusiastically. It also prepares those going on to research who will have to develop this skill. Other approaches include games, ${ }^{16}$ videoed role play, ${ }^{9}$ and computer assisted learning. ${ }^{1317}$

\section{ASSESSMENT}

'Students need to know how what they are learning and teachers how well they are teaching'. Assessment is often an afterthought, aimed at marking and ranking the students yet feedback is essential to rectify students' and teachers' deficiencies. Course innovations need careful assessment and this must be an early consideration when designing a child health course. ${ }^{18}$

\section{Where to teach?}

The teaching hospital - full of science and rigorous thought, occupied by researchers investigating rare diseases that may have importance beyond their incidence if they illustrate basic pathophysiological principles? The district general hospital - a broader exposure, run by clinicians with favourite 'recipes', proved in the heat of the kitchen but less rigorously tested? Alternatively the community - practically difficult but providing experience of common conditions and demonstrating the struggle that child rearing is for most families? Experience at St Mary's Hospital Medical School suggests that students prefer the district general hospital and consultant reports indicate that they perform better when away from St Mary's. Both are needed, however; the experience in a district general hospital would be difficult to assimilate without the preparation provided by a preceding introduction.

Within the hospital changing patterns of care dictate the community and hospital paediatrics need to be more closely integrated. Children are in the ward for a decreasing length of time and community care is being built up. The teaching hospital with its surrounding community facilities can provide this broad exposure while the district general hospital can give the student the opportunity to clerk patients as they come through the unit. Further research is needed but Lawson and Moss have shown that innovative teaching practices in outpatients can improve service to the community and also be used to teach students. ${ }^{19}$

\section{When should we teach?}

The GMC directives clearly propose further integration of the clinical and preclinical courses. Child health has much in common with the preclinical sciences of embryology, genetics, biochemistry, and physiology. This provides an exciting opportunity to develop imaginative courses such as those at Sheffield ${ }^{20}$ and Newcastle upon Tyne, ${ }^{21}$ allowing detailed study of a family and longitudinal observation of child development. Integration places an imperative on paediatricians to involve themselves with course planning. If there is no representation at curriculum planning, there is a real danger that the teaching of child health will be fragmented and incorporated into many different modules.

\section{Conclusion}

Undergraduate teaching has been the poor 
relation and while medical schools are oversubscribed there will be limited consumer pressure for improvement. The GMC directives offer a unique opportunity to encourage colleagues to reinvigorate their teaching. The present mood for change should be exploited to allow teacher to talk to teacher, to share ideas, methods and resources; Price and Mitchell have shown that staff value such dialogue. ${ }^{22}$ If teachers approach the task with enthusiasm this might be an infectious disease we would be happy for students to contract while studying child health.

1 Lowry S. What's wrong with medical education in Britain? $B M F$ 1992; 305: 1277-80.

2 Doran GA. Aspects of the content versus process debate in medical education. Med Educ 1984; 18: 401-5.

3 Anderson J, Graham A. A problem in medical education: is there information overload? Med Educ 1980; 14: 4-7.

4 General Medical Council. Tomorrow's doctors. Recommendations on undergraduate medical education. London: mendations on

5 Bennett RJ, Sackett DL, Haynes RB, et al. A controlled trial of teaching critical appraisal of the clinical literature to of teaching critical appraisal of the clinical

6 Barrows HS. Inquiry: the pedagogical importance of a skill central to clinical practice. Med Educ 1990; 24: 3-5.

7 Barrows HS. Problem based, self directed learning. $\mathcal{F} A M A$ 1983; 250: 3077-80.

8 Weinman J. Communication and learning course. In: Towle $\mathrm{A}$, ed. Innovative learning and assessment. London: Kings Fund, 1994: 11-4.
9 Whitehouse C. Developing a basic communication skills course. In: Towle A, ed. Innovative learning and assessment. London: Kings Fund, 1994: 15-6.

10 Cushing A, Joffe T. Clinical and communication skills workbook assignment. In: Towle A, ed. Innovative learning and assessment. London: Kings Fund, 1994: 88-9.

11 Foulds DM, Sterling R, Wood PR, Sterling J, Littlefield JH. The current place of learning objectives in paediatrics. Med Educ 1989; 23: 407-8.

12 Miller $M$. Changing medical education in western Europe. Med Educ 1978; 12 (suppl 2): 28-33.

13 Garrud P, Chapman IR, Gordon SA, Herbert $M$. Nonverbal communication evaluation of a computer assisted learning package. Med Educ 1993; 27: 474-8.

14 Petersen S, Howard L. Student-led organisation of practical time in physiology. In: Towle A, ed. Innovative learning time in physiology. In: Towle A, ed. Innovative lear

15 Taylor D. Peer assessment and presentation skills. In: Towle A, ed. Innovative learning and assessment. London: Kings Fund, 1994: 90-1.

16 Blair M. Innovations in child health teaching. In: Towle A, ed. Innovative learning and assessment. London: Kings Fund, 1994: 37-8.

17 Underwood JCE, Cotton DWK, Cross SS. Interactive compact disc (CD-1) and multimedia for student-centred learning. In: Towle $\mathrm{A}$, ed. Innovative learning and assessment. London: Kings Fund, 1994: 73-4.

18 Rolfe I, McPherson J. Formative assessment: how am I doing? Lancet 1995 ; 345: 837-9.

19 Lawson M, Moss F. The move from inpatient teaching. In: Towle A, ed. Innovative learning and assessment. London: Kings Fund, 1994: 46-9.

20 Fox NJ, Joesbury H, Hannay DR. Family attachments and medical sociology: a valuable partnership for student medical sociology: a valuable part

21 Forster DP, Drinkwater CK, Corradine A, Cowley K. The family study and survey at Newcastle medical school: an integrated approach. Med Educ 1992; 26: 110-5.

22 Price DA, Mitchell CA. A model for clinical teaching and learning. Med Educ 1993; 27: 62-8.

\title{
Core knowledge, skills, and attitudes for undergraduates: kindling curiosity
}

\author{
J D Baum
}

The body of knowledge applicable to the practice of medicine is vast and growing exponentially and there is no possibility, and never was, of teaching the subject comprehensively. Rather, students need to be shown how to find their way to and through the body of knowledge in order to apply it safely to the care of the individual or population concerned. Thus, for the study of paediatrics and child health, undergraduate students need a clear syllabus to define the core knowledge, experience, and skills to be acquired. This should be supported by a basic text, selective additional reading, or the equivalent information in electronic format. The whole needs to be brought to life through contact with clinical teachers, and the clinical drama of the lives of children and their families. The students' attitudes to learning will inevitably be affected by the content and structure of their examinations in paediatrics and child health and how these in turn relate to their graduation prospects.

The agenda for learning and teaching the Health, Royal Hospital for Sick Children, for Sick Children, St Michael's Hill,
Bristol BS2 8BJ

Correspondence to: Professor Baum. medicine of childhood differs slightly but significantly from the medicine of adulthood. In addition to classical anatomy, and the anatomy of the genome, students need to focus on the anatomy of the family and of the society in which the family live. They need to be encouraged to take as much interest in the physical sign of the parent not present at the bedside, of the total family's attendance in the outpatient clinic, of the distress signals of silence or overactivity, as in feeling the tip of an enlarged spleen or demonstrating a positive Babinski reflex.

In these days of the nightmare of health service reforms, it is perhaps surprising and heartening to note the emergence of an immensely important (if obvious) principle, namely that medical education should be lifelong, bridging the great divides of the past, at graduation, at collegiate membership, and consultancy appointment. The essence of continuing medical education for consultants should be no different from the education of undergraduate students of medicine: we have to establish firm but impermanent foundations of core knowledge on which to build a theoretical and applied approach to medical practice drawn from the ever changing technology, language, and database of the clinical sciences. The 'senior' and 'junior' students may then sit and learn together, provided they remain hungry for knowledge. My central concern is 